\title{
La minería del wolframio en el noroeste de la península ibérica (1939-1959). La Peña del Seo
}

\author{
Diego Castro Franco \\ epistates@hotmail.com \\ Director: Dr. José Javier Rodríguez González \\ Tesis doctoral defendida el 19 de septiembre de 2017
}

El 1 de abril de 1939 el general Francisco Franco anunció su victoria en la Guerra Civil española (1936-1939), conflicto en el que habían muerto unas 500.000 personas. De este modo, quedó definitivamente establecida una dictadura bajo una sangrienta represión (se produjeron al menos 28.000 ejecuciones "políticas" entre 1939 y 1945) ${ }^{1}$ y el control estatal de los medios de comunicación (Ley de Prensa del 22 de abril de 1938). Cinco meses después comenzaba la II Guerra Mundial (1939-1945) con la invasión de Polonia por parte de la Alemania nazi. En relación a este nuevo conflicto, España se declaró neutral inicialmente, pero tras los espectaculares triunfos militares alemanes (desde la conquista de Polonia a la de Francia) adoptó una postura de "no beligerancia" el 12 de junio de 1940. Este cambio de actitud quizás podía anticipar una posible entrada española en la contienda, aunque en realidad significó participar de una manera "indirecta" a favor de uno de los bandos (principalmente el Eje, donde militaban Alemania, Italia y Japón), pero sin necesidad de entrar abiertamente en la guerra. ${ }^{2}$ Esa participación "indirecta" de España en la II Guerra Mundial a favor de Alemania y en contra de los Aliados (el Reino Unido y luego Estados Unidos y la Unión Soviética) se plasmó en las facilidades dadas a submarinos y barcos alemanes para avituallarse en puertos españoles, en la creación en 1941 de la División Azul o unidad militar de voluntarios españoles (fueron un total de 47.000) enviada a ayudar al ejército alemán en la invasión de la Unión Soviética, en la ostentosa germanofilia de la prensa española, en la libertad de actuación de los Servicios de Inteligencia alemanes en España, etc. Asimismo, y merced a la enorme deuda de guerra que había contraído Franco con Alemania a causa de la Guerra Civil española (unos 372 millones de marcos equivalentes a más de 1.600 millones de pesetas, ya que el cambio oficial era por entonces de 4,34 pesetas por marco alemán), hubo una importante ayuda económica de

En 1940 la población reclusa en España era de 233.373 personas y en 1941 de 159.392. Téngase en cuenta que casi todas las cárceles presentaban condiciones insalubres. Actualmente el número de reclusos en España es inferior a 65.000. Véase PAYNE, S. G. (2005). El Franquismo. Primera Parte, pp. 34-35.

2 Para mayor información sobre este periodo de la historia de España, véase PAYNE, S. G. (2008). Franco y Hitler. España, Alemania, la Segunda Guerra Mundial y el Holocausto. 
España a Alemania que consistió en el envío de productos agroalimentarios y minerales vitales para la industria bélica germana. ${ }^{3}$ Minerales donde destacó el wolframio.

El wolframio era importante para la producción armamentística porque se utilizaba básicamente para endurecer el blindaje de los tanques y para fabricar proyectiles antitanque con mayor capacidad de perforación. A la demanda alemana de este mineral pronto se sumó también la británica y estadounidense, desencadenándose una feroz competencia entre las potencias beligerantes que estimuló el aumento de la producción en las minas españolas y que el precio de venta se disparase. Por ejemplo, entre enero y noviembre de 1943, cotizándose la tonelada de wolframio entre 170.000 y 275.000 pesetas, el Reino Unido adquirió un total de 2.563 toneladas frente a las 1.185 toneladas adquiridas por Alemania. ${ }^{4} \mathrm{Al}$ tratarse de un negocio altamente beneficioso el gobierno español quiso participar gravando con enormes impuestos las exportaciones: en abril de 1942 el impuesto de exportación de wolframio ascendía a 1.250 libras esterlinas por tonelada y en enero de 1943 se había doblado esa cifra. ${ }^{5}$ En 1943 el valor de la exportación del mineral había sido de 1.500 millones de pesetas, de las que el Instituto Español de Moneda Extranjera había ingresado su equivalente en divisas, Hacienda había cobrado 600 millones y el resto se había repartido entre industrias, salarios, etc. ${ }^{6}$ En 1943, con una producción de 3.902 toneladas, España era el quinto

\footnotetext{
3 Ángel Viñas, estudiando datos no oficiales (y no divulgados) que manejaron internamente las autoridades españolas, concluyó que hasta 1943 los suministros al Eje por parte de España fueron consistentemente por delante de los efectuados al Reino Unido y Estados Unidos (Aliados). En 1940, periodo en el cual las comunicaciones con Alemania estuvieron parcialmente suspendidas, se exportaron productos por 25 millones de pesetas-oro a las potencias del Eje (mucho más a Alemania que a Italia) y por 162 a las potencias aliadas. En 1941 las corrientes experimentaron un giro radical: las primeras recibieron productos por 206 millones y las segundas solo por 43. En 1942 continuó esta tendencia con 236 millones de pesetas-oro dirigidas al Eje, mientras que las destinadas a los Aliados empezaron a aumentar hasta situarse en 96 millones. El clímax se alcanzó en 1943 con exportaciones al Eje por valor de 290 millones de pesetas-oro y casi 203 millones para los Aliados. Solo en 1944 la tendencia cambió, en parte debido al corte de las comunicaciones por Francia tras la reconquista de dicho país por los Aliados: 173 millones para el Eje frente a los 417 millones para los Aliados. Comercialmente hablando, España no se portó nada mal con el Eje durante la II Guerra Mundial. De hecho, España llegó a soportar un saldo anual acreedor cada vez mayor con Alemania, un auténtico préstamo encubierto. Véase VIÑAS, Á. (2016). Sobornos. De cómo Churchill y March compraron a los generales de Franco, p. 206.

4 Archivos Nacionales del Reino Unido (TNA). FO 837/782 y FO 837/786. Las cifras pueden variar con respecto a las que aportan otros autores.

5 Según Ángel Viñas, el cambio oficial en 1941 era de 41,50 pesetas por libra esterlina, por lo que en abril de 1942 el impuesto de exportación de wolframio ascendía a unas 51.875 pesetas (de la época) por tonelada. Expresar el contravalor de la peseta en términos actuales es una tarea difícil. Siguiendo el concepto de José Ángel Sánchez Asiaín de "capacidad relativa real de gasto equivalente", es decir, en términos del sacrificio que conllevaría generar o disponer de esa renta; se puede establecer que una peseta en 1940 equivaldría actualmente a 11,42 euros. En 1941 la equivalencia de una peseta puede situarse en 10,44 euros, en 8,70 euros en 1942 y en 8,15 en 1943. Por lo tanto, esas 51.875 pesetas por tonelada en concepto de impuesto de exportación de wolframio del año 1942 equivaldrían hoy en día a más de 450.000 euros. Véase SÁNCHEZ ASIAÍN, J. Á. (2014). La financiación de la guerra civil española, pp. 949-950 y VIÑAS, Á. et al. (1979). Política comercial exterior en España (1931-1975), vol. 1, p. 278.

6 COLLADO SEIDEL, C. (2016). El telegrama que salvó a Franco. Londres, Washington y la cuestión del Régimen (1942-1945), p. 86 y THOMÀS, J. M. (2010). La batalla del wolframio. Estados Unidos y España de Pearl Harbor
} 
productor mundial de wolframio por detrás de China, Estados Unidos, Portugal y Bolivia. Entre 1942 y 1944 se produce en España el mismo tonelaje que la suma de la producción en los 37 años anteriores, suponiendo el 5,1\% de la producción mundial. La mayor parte de la producción de España procedía de la multitud de pequeñas minas explotadas de manera informal por los aventureros. ${ }^{7}$

Efectivamente. Paralelo al mercado oficial de exportación de wolframio se abrió paso un intenso contrabando debido a la elevada demanda internacional. De hecho, Jordi Catalán calcula el importe del tráfico clandestino de wolframio español durante el intervalo 1940-1942 en alrededor de 600 millones de dólares. ${ }^{8}$ La cifra parece inaudita si pensamos que las reservas de oro del Estado español durante esa época no alcanzaban los 100 millones de dólares, o que el valor oficial de las importaciones españolas durante un año cualquiera de la II Guerra Mundial estuvo por debajo de los 250 millones de dólares. ${ }^{9}$ Los principales yacimientos de wolframio se concentraban en Portugal, mientras que en España estaban en la zona occidental, particularmente en Galicia. ${ }^{10}$ En el caso del Bierzo destacó por su importancia el enclave minero de la Peña del Seo (Cadafresnas). El comercio de este mineral convirtió Galicia en particular, y el noroeste peninsular en general, en una zona de extraordinaria relevancia durante la guerra. Buques mercantes, barcos de guerra y submarinos en su desplazamiento por el océano Atlántico tomaban como referencia las costas gallegas. Por ello, los Servicios de Inteligencia de Alemania y del Reino Unido incrementaron su presencia en el noroeste de España, convirtiéndose en una de las principales áreas geoestratégicas y económicas. ${ }^{11}$ Es indudable que el Bierzo, dada su proximidad con el territorio gallego, también tuvo que quedar insertado dentro de este espacio geoestratégico.

El comercio de wolframio adquirió gran importancia a la hora de influir en las relaciones internacionales de España con las potencias beligerantes. ${ }^{12} \mathrm{~A}$ su vez, los altos

a la Guerra Fría (1941-1947), pp. 122-123 y 203.

7 Archivo de la Sociedad Estatal de Participaciones Industriales (SEPI), caja 1.

8 Según Manuel Ros Agudo, el cambio oficial fijo en esos años era de 12 pesetas por dólar (en el mercado negro podía alcanzar las 45 pesetas), por lo que el contrabando de wolframio entre 1940 y 1942 se puede cifrar entre los 7.200 y los 27.000 millones de pesetas de la época. Estas cantidades equivaldrían actualmente a unos 75.168 o 281.880 millones de euros, teniendo en cuenta que una peseta en 1941 equivaldría a 10,44 euros en la actualidad. Téngase también en cuenta que el salario medio de comienzos de la década de 1940 en España era aproximadamente de 10,60 pesetas diarias. Véase ROS AGUDO, M. (2002). La guerra secreta de Franco (1939-1945), p. 148-149.

9 CATALÁN, J. (1995). La economía española y la Segunda Guerra Mundial, p. 186.

10 Archivo de la Sociedad Estatal de Participaciones Industriales (SEPI), caja 34.

11 GRANDÍO SEOANE, E. (2015). "No solo Wolframio. Galicia, campo de juego de las redes de inteligencia durante la Segunda Guerra Mundial”. Revista Universitaria de Historia Militar, 4 (n 8), p. 102.

${ }^{12}$ El wolframio vertebró la política exterior franquista durante la II Guerra Mundial hasta el punto de que Estados Unidos y el Reino Unido aprobaron el 29 de enero de 1944 un embargo de petróleo contra España para forzarle a que cesara totalmente sus exportaciones de wolframio a Alemania. Utilizando el recurso del arma económica 
precios a los que se pagaba el mineral estimularon que miles de individuos, viendo la posibilidad de obtener sustanciosos ingresos, se convirtieran de la noche a la mañana en mineros improvisados dispuestos a extraer por su cuenta y riesgo el wolframio para venderlo en el mercado negro a los intermediarios y a los agentes británicos, estadounidenses o alemanes que pululaban clandestinamente por los alrededores de las zonas mineras. Hasta 300 pesetas se llegó a pagar por un kilogramo de wolframio en el mercado negro, aunque los precios fluctuaban constantemente. El Bierzo, a causa de ese tipo de redes comerciales desarrolladas básicamente en torno a la Peña del Seo, no fue ajeno a esa situación. Localidades como Ponferrada adquirieron el sobrenombre de la "Ciudad del Dólar". Esta denominación tenía un doble sentido: por una parte aludía al rápido enriquecimiento de determinados personajes, y por otra, a la eclosión en la ciudad de diversos bares y prostíbulos financiados con dinero negro generado por el contrabando de wolframio. De hecho, uno de los prostíbulos fundados más famosos se llamó El Dólar. ${ }^{13}$

Tanto los Servicios de Inteligencia alemanes como sus homólogos británicos y estadounidenses enviaron a España agentes y espías que participaron en la "batalla del wolframio", ${ }^{14}$ es decir, en la lucha por adquirir la mayor cantidad del codiciado mineral con el fin de privar del mismo al enemigo. A su vez, ambos bandos recurrieron también a la utilización de españoles como agentes, colaboradores e informadores. Estos solían ser voluntarios que al vivir muchas veces en los límites de la subsistencia prestaban sus servicios para obtener así dinero de una forma rápida. A menudo ni siquiera fueron conscientes del grado de peligrosidad que conllevaba la participación en este tipo de actividades adscritas al campo del espionaje. Tal y como señalaba un informe británico

los Aliados pretendían suprimir el comercio hispano-alemán que pivotaba en torno al mencionado mineral. A su vez, buscaban reducir la capacidad armamentística alemana para acelerar su derrota en la guerra y también acabar con el costoso programa anglo-estadounidense de compras preventivas de wolframio. Finalmente Franco, viendo las graves consecuencias que estaba sufriendo la economía española a causa del embargo, llegó a un acuerdo el 2 de mayo: España aceptó, entre otras cosas, una importante reducción de las cuotas de exportación de wolframio a Alemania a cambio de que los Aliados reanudaran el suministro petrolífero. Sin embargo, el contrabando de wolframio siguió siendo muy elevado. De hecho, Alemania, tanto por medios legales como ilegales, pudo importar 834,6 toneladas entre enero y septiembre. Véase THOMÀS, J. M. (2010). op. cit., pp. 117-203.

${ }^{13}$ Durante la II Guerra Mundial, la Peña del Seo se convirtió en una especie de "salvaje oeste" donde las numerosas personas que pululaban por el paraje para extraer ilegalmente wolframio protagonizaron y sufrieron robos, tiroteos y accidentes mortales. Así lo atestiguan multitud de testimonios orales recopilados y documentación archivística consultada a tal efecto.

${ }^{14}$ Eduardo Martín de Pozuelo e Iñaki Ellakuría aportan un listado de agentes y/o colaboradores (tanto españoles como extranjeros) que trabajaban para los Servicios de Inteligencia alemanes, británicos y estadounidenses en España. Véase MARTÍN DE POZUELO, E. y ELLAKURÍA, I. (2008). La guerra ignorada. Los espías españoles que combatieron a los nazis, pp. 299-304. 
de mayo de 1944, algunas de esas personas exponen su libertad y sus vidas con objeto de conseguir que disminuyan abastecimientos que son vitales para el adversario. ${ }^{15}$

Abordemos ahora brevemente el caso de la mina de la Peña del Seo a la que anteriormente hemos aludido. Ya señalamos que las potencias beligerantes organizaron en el noroeste peninsular una nutrida red de agentes, intermediarios e informadores para coordinar la compra-venta del mineral en el mercado negro. Uno de estos intermediarios fue un coruñés llamado Joaquín Santos Bugallo, que presumiblemente vendía wolframio de contrabando a agentes británicos tras comprar él mismo el mineral que recogían otros mineros informales, principalmente de la mina de Casayo (Orense). Bugallo había montado junto a otros socios un almacén clandestino en el pueblo orensano de Quereño (situado en la línea fronteriza entre Orense y el Bierzo) para purificar allí el wolframio que adquiría antes de venderlo. Posteriormente Bugallo se enteró de las posibilidades de negocio que ofrecía el wolframio de la Peña del Seo y el 1 de agosto de 1944, tras obtener los correspondientes permisos y licencias gubernamentales, culminó el registro definitivo de la llamada mina Currito en la Peña del Seo. De este modo, Bugallo dejó de lado el comercio ilegal de wolframio y se centró en la minería legal.

Según la Estadística Minera y Metalúrgica de España del año 1944, la producción de la mina Currito fue de solo 1,116 toneladas, llegando al año siguiente a poco más de dos toneladas. ${ }^{16}$ La forma de extraer el mineral era todavía primitiva y apenas se diferenciaba de la que realizaban los aventureros. Una quincena de trabajadores utilizaban mazas para extraer el mineral que luego introducían en sacos para transportarlos (con caballerías o sobre los hombros) hasta un lavadero artesanal construido en la parte de abajo, donde se limpiaba el mineral quitándole los restos de cuarzo para llevarlo a vender después a La Coruña. Lo cierto es que no se estableció una explotación industrial tecnificada y apenas se profundizó en el interior de la mina. Además, desde el primer momento Bugallo tuvo dificultades en la explotación de la Peña del Seo, ya que los mineros informales, acostumbrados a extraer allí el mineral libremente, se negaban a aceptar la privatización de la mina y a perder la fabulosa fuente de ingresos que les proporcionaba el contrabando de wolframio. A ello se sumaba la inseguridad derivada de la presencia guerrillera en la zona. Bugallo se mostró dispuesto a hacer efectiva la posesión plena de la mina y contrató vigilantes armados, ya que los robos de mineral y los enfrentamientos a tiros con esas cuadrillas eran

\footnotetext{
15 Archivos Nacionales del Reino Unido (TNA). PRO T 263/4.

${ }_{16}$ Archivo del Instituto Geológico y Minero de España (IGME). Estadística Minera y Metalúrgica de España. Provincia de León. Años 1944 y 1945.
} 
comunes. Sin embargo, las dificultades para lograr una explotación rentable y segura, la imposibilidad de acabar por completo con los asaltos de las cuadrillas de mineros informales y la progresiva caída del precio del mineral conforme se avecinaba el fin de la II Guerra Mundial, fueron los factores determinantes que provocaron que finalmente Bugallo abandonara su actividad y vendiera la mina Currito en 1947. Posteriormente la Peña del Seo vivirá un nuevo proceso de explotación industrial de la mano de la empresa Montañas del Sur, que privatizó la mina y se dispuso a explotar el mineral de nuevo, pero esta vez de una forma tecnificada e industrial. Aprovechándose de una nueva coyuntura internacional favorable para exportar wolframio a raíz del estallido de la Guerra de Corea, se erigieron diversas instalaciones (lavaderos, molinos...), se contrató mano de obra asalariada y se construyó un poblado para los trabajadores.

\section{FUENTES ARCHIVÍSTICAS}

- Archivo del Instituto Geológico y Minero de España (IGME). Madrid.

- Archivo de la Sociedad Estatal de Participaciones Industriales (SEPI). Madrid.

- Archivos Nacionales del Reino Unido (TNA). Londres.

\section{FUENTES BIBLIOGRÁFICAS}

CATALÁN, J. (1995). La economía española y la Segunda Guerra Mundial. Ed. Ariel.

COLLADO SEIDEL, C. (2016). El telegrama que salvó a Franco. Londres, Washington y la cuestión del Régimen (1942-1945). Ed. Crítica.

GRANDÍO SEOANE, E. y RODRÍGUEZ GONZÁLEZ, J. (eds.) (2012). War Zone. La Segunda Guerra Mundial en el Noroeste de la Península Ibérica. Ed. Eneida.

GRANDÍO SEOANE, E. (2015), "No solo Wolframio. Galicia, campo de juego de las redes de inteligencia durante la Segunda Guerra Mundial". Revista Universitaria de Historia Militar, 4 (no 8), pp. 101-117.

MARTÍN DE POZUELO, E. y ELLAKURÍA, I. (2008). La guerra ignorada. Los espias españoles que combatieron a los nazis. Ed. Debate.

PAYNE, S. G. (2005). El Franquismo. Primera Parte. Ed. Arlanza.

PAYNE, S. G. (2008). Franco y Hitler. España, Alemania, la Segunda Guerra Mundial y el Holocausto. Ed. La Esfera de los Libros.

ROS AGUDO, M. (2002). La guerra secreta de Franco (1939-1945). Ed. Crítica. 
SÁNCHEZ ASIAÍN, J. Á. (2014). La financiación de la guerra civil española. Ed. Crítica.

SERRANO, S. (1988). La guerrilla antifranquista en León (1936-1951). Ed. Siglo Veintiuno de España.

THOMÀS, J. M. (2010). La batalla del wolframio. Estados Unidos y España de Pearl Harbor a la Guerra Fría (1941-1947). Ed. Cátedra.

VIÑAS, Á. et al. (1979). Política comercial exterior en España (1931-1975), vol. 1. Ed. Servicio de Estudios Económicos. Banco Exterior de España.

VIÑAS, Á. (2016). Sobornos. De cómo Churchill y March compraron a los generales de Franco. Ed. Crítica.

\section{FUENTES HEMEROGRÁFICAS}

- $A B C$

- Diario de León

- El Mundo

- España Popular

- Nuestra Bandera 